\title{
Bilateral Spontaneously Resolving Galactocele in an 18 Month Old Boy: A Case Report
}

\author{
S. Aminou and Z. Imane
}

\section{ABSTRACT}

Galactoceles in children, either cystic or pseudotumors, are described in the literature as a rare cause of increasing breast size and can appear in males. We report a case of galactocele in a 18-month-old male, treated at our institution. The patient presented with bilateral tumor breast that had appeared 6 months earlier with no pain, signs of inflammation, or nipple secretion. Twenty-nine cases found in the literature emphasize the importance of including galactocele in the differential diagnosis of benign breast masses in infancy.

Keywords: Bilateral galactocele, breast ultrasound, infant, breast, male.

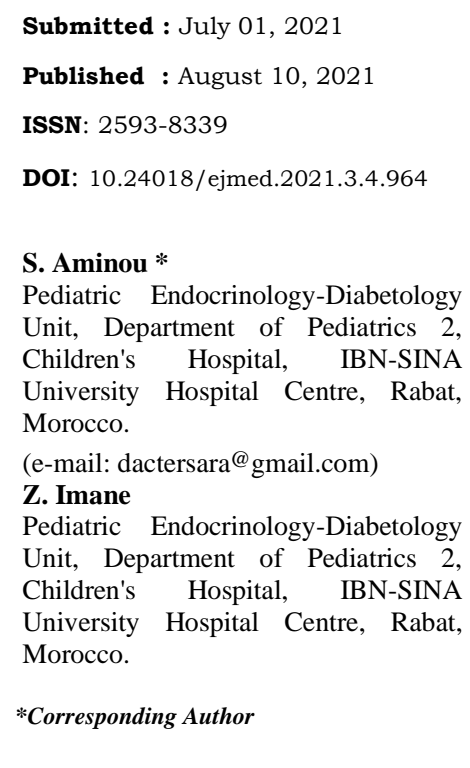

\section{INTRODUCTION}

Galactocele is a benign cystic or pseudo-cystic breast tumor containing a lactescent fluid, usually seen in lactating women, its occurrence is exceptional in children, it is seen in infants after the genito-mammary crisis [1]. Its etiology remains a mystery. Our goal is to highlight the importance of galactocele as a benign condition that should be included in the differential diagnosis of infant breast masses.

\section{PATIENT AND OBSERVATION}

We report the case of an infant A. male aged 18 months, who was referred to us for progressive bilateral breast swelling since the age of 6 months. Born vaginally after an uneventful full-term pregnancy. There is no history of breast discharge, trauma, infection, drug use during pregnancy, or contact with estrogen-based products, or history of breast disease in the family. On physical examination, he presented anthropometric parameters consistent with normal development for the age. Palpation of the breasts found two hard renitent masses, protruding elevating the two nipples, measuring approximately $7 \mathrm{~cm}$ in long axis, painless, absence of nipple discharge, without inflammatory signs opposite nor of satellite lymphadenopathy (Fig. 1). The external genitalia were normal male. Both testes were present in the scrotum, of normal size, with no palpable mass. There were also no clinically detectable endocrine abnormalities. A complete biological investigation including a hormonal balance was found to be normal: $\mathrm{FSH}=1.56 \mathrm{mIU} / \mathrm{ml}, \mathrm{LH}<$ $0.07 \mathrm{mIU} / \mathrm{ml}$, Beta-HCG $<2 \mathrm{mIU} / \mathrm{ml}$, testosterone $<0.05$ $\mathrm{ng} / \mathrm{ml}, \mathrm{TSH}=1.675 \mathrm{iUI} / \mathrm{ml}, \mathrm{T} 4=10 \mathrm{ng} / \mathrm{l}, \mathrm{AFP}=7 \mathrm{ng} / \mathrm{ml}$, Prolactinemia $=24 \mathrm{ng} / \mathrm{ml}$, Estradiol $=15 \mathrm{pg} / \mathrm{ml}$. The breast ultrasound revealed multiple discreetly compartmentalized fluid images, some of which have impure fluid content, the largest measuring $10 \times 7 \mathrm{~mm}$, an appearance consistent with bilateral mammary galactocele. (Fig. 2.) Pelvic and scrotal ultrasound is without abnormality. Bone age is 18 months corresponding to chronological age. Cyto-puncture was indicated but the parents refused. The clinical follow-up for one year revealed a spontaneous regression of the galactocele (Fig. 3).

\section{DISCUSSION}

Galactocele is an extremely rare cause of breast swelling in men. The majority of previously published cases have been diagnosed in children and infants, except for a single 75-year-old man [2]. So far, only 29 cases have been reported in the literature [3]. The average age of onset is 7 months. Pettinato and Bower, had studied breast pathologies in 320 infants and children, found unilateral galactocele only in three cases of male children aged 12 months, 21 months, and 6 years [4]. The galactocele in children and infants is generally unilateral in $67 \%$ of cases [4] but can- as in our case-be bilateral. Its etiology remains unknown. However, three factors have been incriminated:

1. Stimulation by prolactin especially in bilateral forms, its 
origin could therefore be secondary to trans-placental transmission of hormones, but this does not explain its unilateral tendency, its exclusivity in male sex, nor its occurrence in older children.

2 . The presence of secretory cells within a cystic retention which, following trauma, can cause an inflammatory reaction causing the lesion to persist.

3. The presence of a duct obstruction causing the accumulation of fluid without there being any new ductal formation, which causes fluid accumulation and formation of galactocele [5].
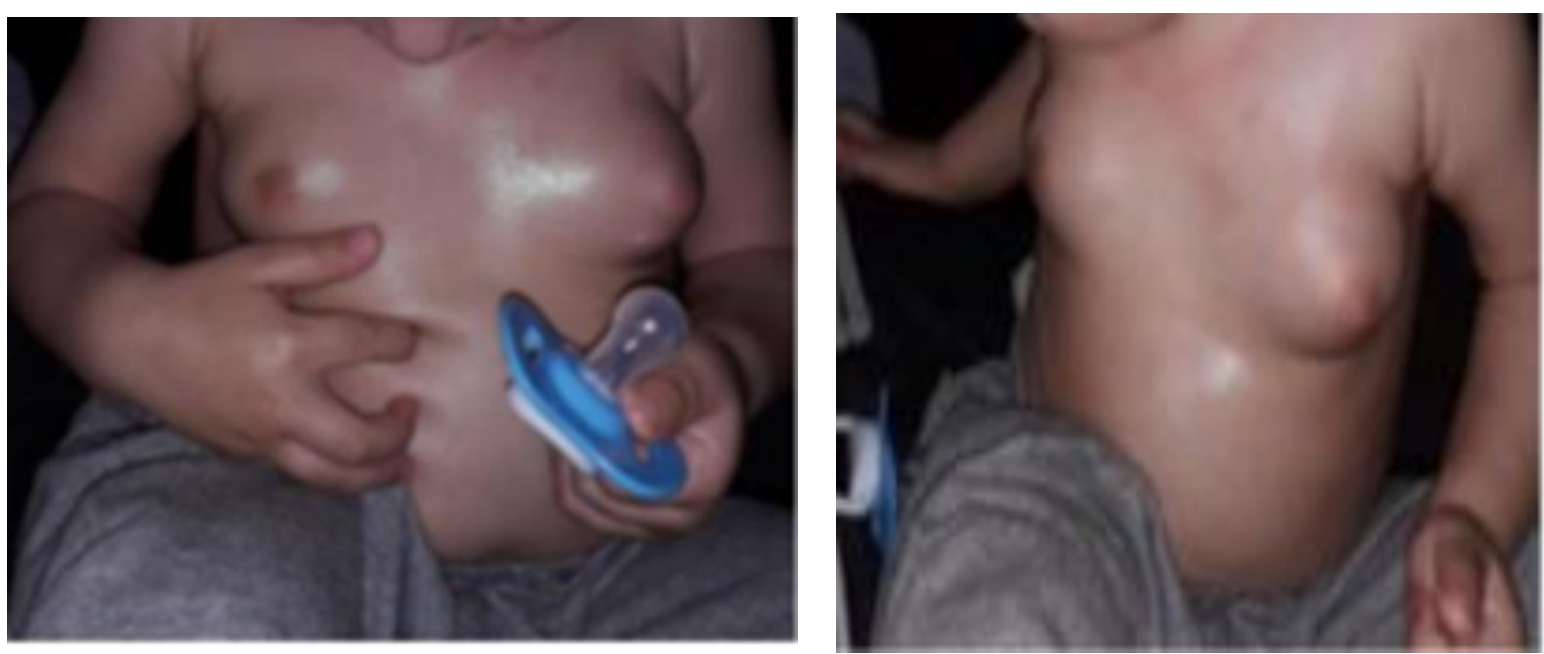

Fig. 1. Clinical aspect of a bilateral galactocele.
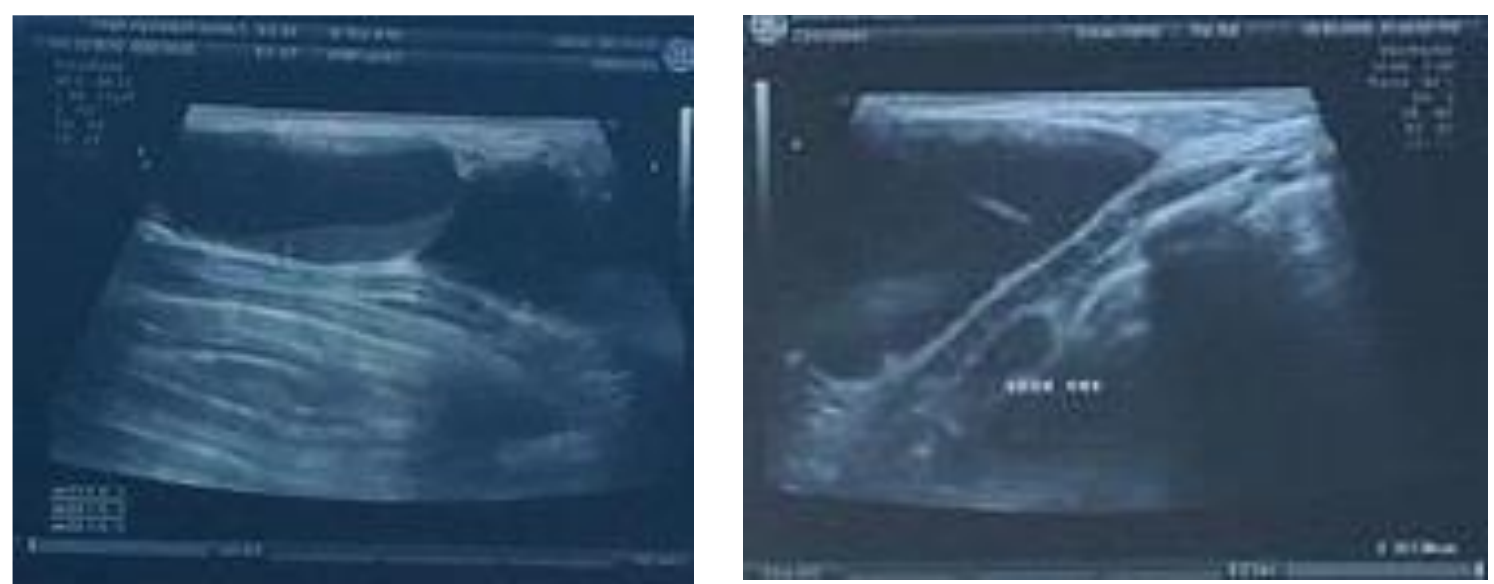

Fig. 2. Heterogeneous anechoic cystic images containing septa, compatible with a galactocele.
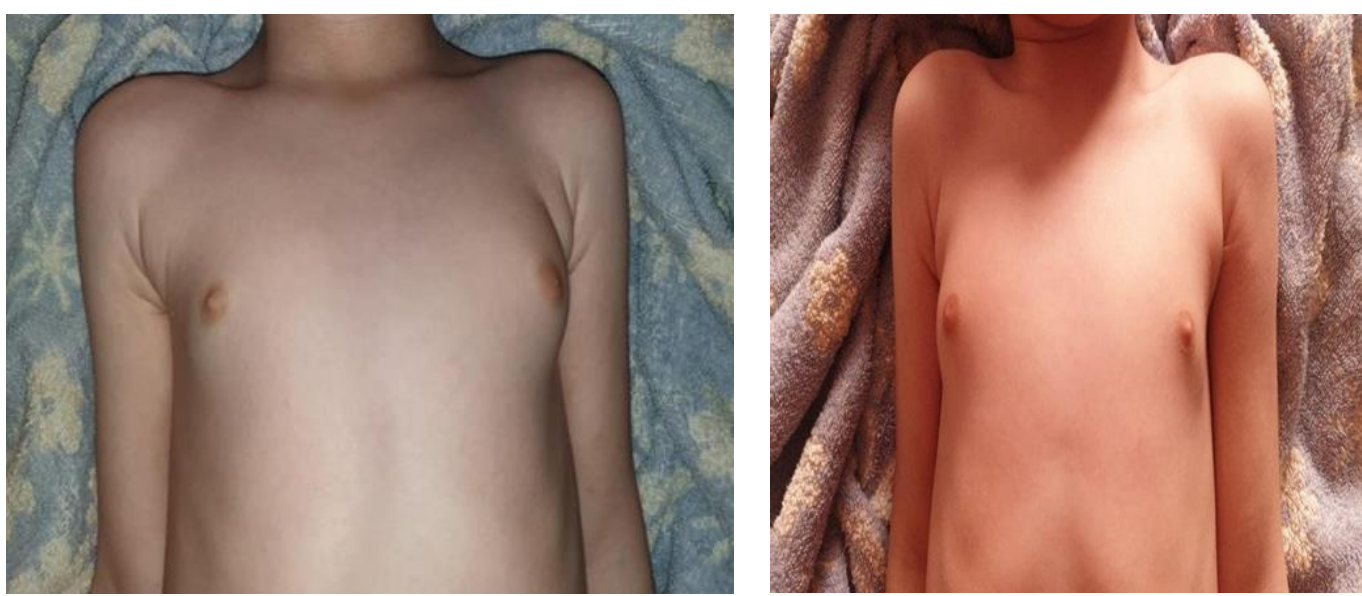

Fig. 3. Spontaneous regression of the galactocele.

Studies have shown that increased IGF1 levels following growth hormone therapy contributed to the development of galactocele [6]. No specific cause had been identified in our patient. Galactocele is a generally isolated clinical feature. However, it can be associated with certain endocrine pathologies. Rahman et al published a case of galactocele associated with congenital hypopituitarism [7], another case of galactocele with Down syndrome and congenital hypothyroidism during the neonatal period [8]. Galactocele usually manifests as progressive, painless, firm breast swelling with no inflammatory reaction. Three reported cases were associated with an isolated congenital malformation: one case of renal dysplasia, one case of interventricular communication and one case of cleft lip [1]. 
Hyperprolactinemia has been present in two pediatric cases of galactocele [9]; the first was an infant with persistent hyperprolactinemia and multiple birth defects including cleft palate, facial dysmorphia (hypertelorism, macroglossia) and syndactilia. The second case was an 11-month-old boy, who was normal except for hyperprolactinemia with nipple discharge [10]. On ultrasound, the classic image is of a welldefined cyst, with a thin wall, the contents are echogenic or hypoechoic or mixed [3]. There may be single or multiple lesions, usually oval in shape [2]. Mammography has no indication in the pediatric population, given the difficulties of interpretation in young subjects and the radiating nature of the technique [5]. In imaging, the main differential diagnosis arises with cystic lymphangioma [1]. Ultrasound can easily rule out certain differential diagnoses such as gynecomastia due to the variable appearance of the tissue depending on the stage of its development. Mixed density lesions must be differentiated from intramammary lymph nodes or fibroadeno-lipomas or hamartomas [7]. A hematoma or abscess are easily eliminated in the clinical and biological context. On MRI, galactocele results in a hypersignal lesion on the $\mathrm{T} 1$ and $\mathrm{T} 2$ weighted sequences given the richly protein content of the cystic mass [5]. A liquid-fat level has been described in adults, on the $\mathrm{T} 1$ sequence. Gadolinium injection may cause peripheral enhancement of the cyst wall and septa [5]. The fluid found in cysts can be white and fluid if fresh or having a higher viscosity if the lesion is older. The fluid contains protein, fat, and lactose in different proportions. A mucus test identifies galactose and confirms the diagnosis of milk. The aspiration of lactescent liquid constitutes a diagnostic and therapeutic procedure. However, the diagnosis of galactocele requires the presence of a true breast cyst lined with cubic epithelium containing lactescent fluid. Due to the pressure from the fluid, the epithelium presents areas of sterile necrosis and chronic or acute inflammation [10]. Treatment of galactocele is surgical and consists of complete enucleation of the cyst [2]. In our case, the puncture of the cyst was not performed, then during follow-up, the two cysts had regressed clinically and ultrasonographically within 6 months. It should be noted that this is the second case of pediatric galactocele that resolved spontaneously. In addition, no recurrence was observed after one year.

\section{CONCLUSION}

Although galactocele is rare, clinicians should consider the possibility of this lesion in the presence of any soft, mobile, and non-tender breast mass in children or infants. The ultrasound-fine needle aspiration pairing would be of great diagnostic help. The treatment is surgical.

\section{COMPETING INTERESTS}

The authors declare no competing interests.

\section{AUTHORS' CONTRIBUTIONS}

All the authors have read and agreed to the final manuscript.

\section{REFERENCES}

[1] M.A. Jellalia et al. "Galactocele: a rare cause of breast swelling in children," Journal of Pediatrics and Childcare, 24: 190-193, 2011.

[2] S. Semmar, D. Meskine, S. Fedala, "Bilateral Galactocele in an 18 Month Old Infant," Annals of Endocrinology, vol. 75; page 406, October 2014.

[3] de Chadarevian, J. P., Arthur III, L. G., Rezvani, G. A., Duke, D. S. Davis, W. J., and Faerber, E. N. "The Galactocele of Male Infants: An Intriguing Entity," Study and reflection about a case, with review of the literature, Pediatric and Developmental Pathology, 14(2), 144148, 2011.

[4] Vlahovic, A., Djuricic, S., Todorovic, S., Djukic, M., Milanovic, D., and Vujanic, G. M. "Galactocele in Male Infants: Report of Two Cases and Review of the Literature," European Journal of Pediatric Surgery, 22(03), 246-250, 2012.

[5] Cesur, Y., Çaksen H., Demirtaş İ., Kösem, M., Üner, A., and Özer, R. "Bilateral Galactocele in a Male Infant: A Rare Cause of Gynecomastia in Childhood," Journal of Pediatric Endocrinology and Metabolism, 14(1), 107-110, 2001.

[6] Rahman, N., Davenport, M., and Buchanan, C. "Galactocele in a Male Infant with Congenital Hypopituitarism," Journal of Pediatric Endocrinology and Metabolism, 17(10), 1451-1454, 2004.

[7] Güven A., Hancili S. "Bilateral Galactocele in a Male Infant with Down Syndrome and Congenital Hypothyroidism," Pediatrics International, 55: 116-118, 2013.

[8] Tomasi, P. A., Fanciulli, G., Casti, T., and Delitala, G. "Persistent Hyperprolactinemia and Bilateral Galactocele in a male Infant," International journal of pediatric endocrinology, 2009(1), 1-2, 2009.

[9] C.T. Lau, K.K.Y. Wong, and P. Tam. "Galactocele in a Male Infant with Transient Hyperprolactinaemia: An Extremely Rare Cause of Breast Enlargement in Children," Case Reports in Pediatrics, 2016.

[10] Perez-Bóscollo, A.C., Dutra, R.A., Borges, L.G.S., Gonçalves, E.M.S., Etchebehere, R.M., Rocha, R. L., ... \& Ribeiro, T.C. "Galactocele: An Unusual Cause of Breast Enlargement in Children," Journal of pediatric surgery, 44(7), e1-e3, 2009. 